Orthopäde 2009 · 38:589

DOI 10.1007/s00132-009-1477-8

Online publiziert: 1. Juli 2009

(c) Springer Medizin Verlag 2009

\author{
V. Ewerbeck ${ }^{1} \cdot$ D. Kohn ${ }^{2}$ \\ ${ }^{1}$ Orthopädische Universitätsklinik, Heidelberg \\ ${ }^{2}$ Orthopädische Universitätsklinik, Homburg/Saar
}

\title{
Abschied von Professor Dr. med. Jochen Löhr
}

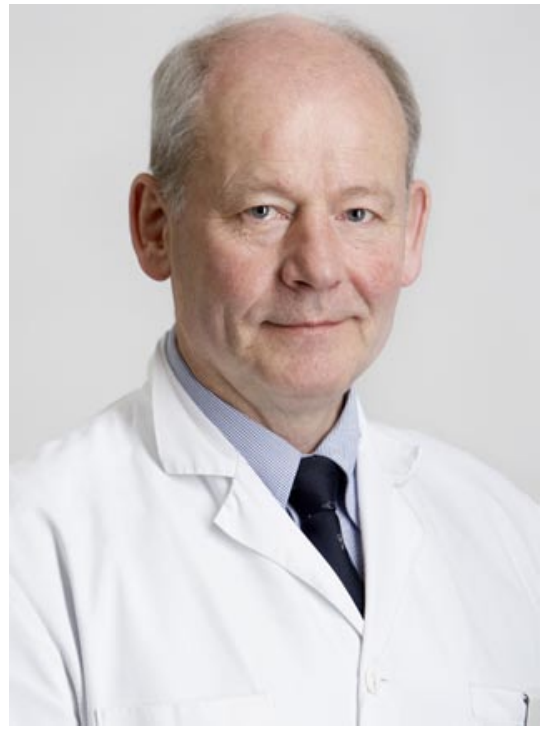

A Joachim Löhr (1951-2009)
Voller Bestürzung und fassungslos haben wir davon Kenntnis nehmen müssen, dass unser Freund und Mitherausgeber unserer Zeitschrift, Herr Professor Dr. med. Jochen Löhr, im Alter von nur 57 Jahren unerwartet während des diesjährigen EFORT-Kongresses in Wien verstorben ist. Jochen Löhr hinterlässt in unseren Reihen eine Lücke, von der wir noch nicht wissen, wie wir mit ihr umgehen sollen.

Seine klinische und wissenschaftliche Expertise haben wir immer wieder miterleben dürfen. Sie beruhte auf einer ganz ungewöhnlich breiten und internationalen Ausbildung, u. a. bei N. Gschwend in Zürich und H.K. Uhthoff in Ottawa. Mit einer Assistenzprofessur kehrte er nach Europa zurück, zunächst nach Würzburg, später nach Zürich, dann als Lehrstuhlinhaber für Orthopädie an das Universitätsklinikum Lübeck, dann an die ENDO-Klinik nach Hamburg und schließlich wieder nach Zürich.

Sehr viele von uns haben ihn auf einer Fülle von nationalen und internationalen Kongressen, Symposien und Kursen als äußerst kenntnisreichen, brillanten und didaktisch beispielhaften Referenten kennen und schätzen gelernt. Stets war er als begeisterter Lehrer immer auf der Suche nach neuen Lehr- und Lernkonzepten, in die er seine wertvollen internationalen Erfahrungen einbringen konnte. Immer wieder hat er auf vielen unterschiedlichen Ebenen zum Thema der Fort- und Weiterbildung die Initiative ergriffen, Gespräche gesucht, Impulse gegeben. Seine wissenschaftliche und didaktische Neugier und Kreativität führte folgerichtig und wiederholt zu Auszeichnungen wis- senschaftlicher Fachgesellschaften im Inund Ausland. Viele von uns kannten Jochen Löhr als begnadeten Redner, der seine Präsentationen in beispielgebender Weise strukturierte und mit dem ihn kennzeichnenden, geradezu "britischen“ Humor hinterlegte.

Im Herausgebergremium unserer Zeitschrift war er ein langjähriger Ratgeber, dessen konstruktive Anstöße uns immer ein Stück weitergebracht haben.

In unserer Trauer sind unsere Gedanken bei seiner Familie, der unser ganzes Mitgefühl gilt.

Die Deutsche Orthopäde und speziell unsere Fachzeitschrift „Der Orthopä$d e$ " verliert mit Jochen Löhr eine weltoffene Persönlichkeit, einen herausragenden Lehrer und einen warmherzigen, liebenswerten Freund. Er ist unersetzbar. Wir werden ihn sehr vermissen.

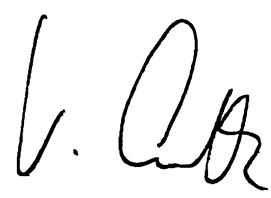

Prof. Dr. V. Ewerbeck

Mitherausgeber

Schriftleitung

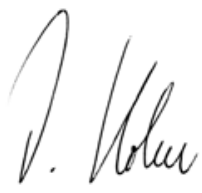

Prof. Dr. D. Kohn

Mitherausgeber

Schriftleitung 